\title{
PERBEDAAN MODEL PEMBELAJARAN KOOPERATIF TIPETHINK PAIR SHARE (TPS) DAN JIGSA W TERHADAP KEMAMPUAN PEMECAHAN MASALAH MATEMATIKA SISWA
}

\author{
Sri Zulhayana
}

Dosen STKIP Budidaya

\begin{abstract}
ABSTRAK
Penelitian ini bertujuan untuk mengetahui apakah ada perbedaan model pembelajaran kooperatif tipe Think Pair Share (TPS) dan Jigsaw terhadap kemampuan pemecahan masalah matematika siswa di kelas VIII SMP Swasta Melati. Pada penelitian ini, desain yang digunakan adalah non equivalent group pre-test post-test design. Sebelum pengujian hipotesis terlebih dahulu dilakukan uji persyaratan analisis data yakni uji normalitas dan uji homogenitas. Normalitas diuji dengan menggunakan titik liliefors dan homogenitas dengan menggunakan uji F. Dari pengujian yang dilakukan diperoleh bahwa kedua sampel berdistribusi normal dan homogen. Pengujian hipotesis dilakukan dengan uji-t dimana pengumpulan data untuk variabel kemampuan pemecahan masalah matematis diperoleh $H_{0}$ ditolak, dan $H_{a}$ diterima. Dari pengujian hipotesis diatas dapat disimpulkan bahwa terdapat perbedaan yang signifikan terhadap model pembelajaran kooperatif tipe think pair share (TPS) dan jigsaw terhadap kemampuan pemecahan masalah matematika siswa pada pokok bahasan SPLDV di kelas VIII SMP Swasta Melati Kec. Hamparan Perak Kab.Deli Serdang tahun ajaran 2018/2019.
\end{abstract}

\section{Kata Kunci :Think Pair Share (TPS), Jigsaw, Kemampuan Pemecahan Masalah}

\section{PENDAHULUAN}

Pemecahan masalah memegang peranan yang sangat penting dalam pembelajaran matematika. Salah satu kegiatan pembelajaran dalam pendidikan matematika yang dianggap penting di dalam sekolah, baik sekolah dasar sampai sekolah menengah, namun pemecahan masalah masih dianggap bagian yang paling sulit dalam matematika. Pentingnya kemampuan pemecahan masalah matematika harus dimiliki siswa di tegaskan oleh Wahyudin dalam Ike Nataliasari, yaitu :(1)Pemecahan masalah yang meliputi metode, prosedur dan strategi merupakan proses inti dan utama dalam kurikulum matematika;(2) Pemecahan masalah merupakan kemampuan dasar dalam belajar matematika.

Pemecahan masalah tidak sekedar menerapkan aturan-aturan yang telah dikuasai, melainkan proses untuk medapatkan seperangkat aturan pada tingkat yang lebih tinggi.Proses pembelajaran hendaknya berusaha mengajak siswa untuk dapat mengembangkan dan meningkatkan kemampuan pemecahan masalah siswa.

Berdasarkan hasil observasi langsung di sekolah, sebagian besar kegiatan pembelajaran masih berpusat pada guru dengan menerapkan metode pembelajaran konvensional. Guru lebih banyak menjelaskan dan memberikan informasi tentang konsep-konsep dari materi 
yang diajarkan. Sementara siswa hanya mendengarkan dan membahas soal-soal yang diberikan oleh guru.

Untuk mengatasi masalah ini dibutuhkan sebuah model yang tepat sehingga dalalm proses pembelajaran siswa lebih berperan dan belajar aktif. Salah satu cara untuk meningkatkan kualitas pembelajaran adalah guru mengajar dengan menentukan dan menggunakan strategi pembelajaran yang tepat. Salah satu model yang diperkirakan dapat digunakan adalah pembelajaran kooperatif (Cooperative Learning).

Menurut Wena dalam Noviyani Florentina,mengatakan bahwa "pembelajaran kooperatif adalah system pembelajaran yang berusaha memanfaatkan teman sejawat (siswa lain) sebagai sumber belajar, disamping guru dan sumber belajar yang ainnya(buku pelajaran).

Model pembelajaran kooperatif masih jarang digunakan padahal berdasarkan hasil-hasil penelitian yang ditelaah oleh Slavin dalam Trianto yang menunjukan bahwa : "teknikteknik pembelajaran kooperatif lebih unggul dalam meningkatkan hasil belajar dibandingkan pengalaman individual atau kompetitif.

Ada beberapa teknik model pembelajaran kooperatif yang dapat dikembangkan dalam pembelajaran matematika, diantaranya teknik tipe TPS (Think Pair Share) dan Jigsaw. Model pembelajaran kooperatif tipe TPS (Think Pair Share) pertama kali dikembangkan oleh Frank Lyman. Dimana pada model pembelajaran kooperatif tipe TPS (Think Pair Share) sering juga disebut dengan berfikir-berpasanganberbagi. Dimana pada model pembelajaran ini siswa dapat belajar dan bekerja sama dalam kelompok kecil yang bersifat kolaborasi. Seperti yang diungkapkan oleh Trianto, TPS (Think Pair Share) merupakan jenis pembelajaran kooperatif yang dirancang untuk memengaruhi pola interaksi siswa.Model kooperatif tipe TPS (Think Pair Share) ini unggul dalam membantu siswa untuk menemukan dan memahami konsep-konsep yang sulit, menumbuhkan kemampuan berfikir kritis dan kemampuan membantu teman saat mereka saling mendiskusikan suatu permasalahan.

Dari kedua pernyataan diatas menunjukan bahwa pentingnya melibatkan peran aktif siswa dalam proses belajar mengajar, melalui pembelajaran kooperatif tipe TPS (Think Pair Share) ini siswa diharpkan mengalami pembelajaran matematika yang lebih menarik, menyenangkan bagi siswa, lebih mengaktifkan siswa dan meningkatkan kemampuan pemecahan masalah matematika siswa sehingga meningkatkan hasil belajar siswa.

Sedangkan model pembelajaran kooperatif tipe Jigsaw adalah model pembelajaran yang dirancang untuk mencapai satu setujuan yang sangat berbeda, bertukar pemahaman bahan instruktur dan memudahkan pemahaman siswa pada sejumlah topik.Pembelajaran model kooperatif tipe Jigsaw membagi materi pembelajaran pada setiap anggota dengan topik-topik yang berbeda. Setiap kelompok asal terdiri atas empat atas atau lima anggota siswa yang berkemampuan heterogen. Setiap anggota kelompok asal berpindah ke kelompok ahli untuk mendiskusikan topik yang sama sampai selesai. Siswa kembali ke kelompok asal untuk mempresentasikan topik pada anggota kelompoknya.

Salah satu materi matematika yang dapat diajarkan dengan penerapan model kooperatif tipe TPS dan Jigsaw adalah materi SPLDV di kelas VIII tingkat SMP. Dalam pembelajaran dengan penerapan model pembelajaran kooperatif tipeTPS dan Jigsaw, materi SPLDV disajikan dengan $m$ engaitkannya dengan kehidupan sehari-hari siswa dan siswa didorong untuk membuat hubungan antara 
pengetahuan SPLDV yang dimilikinya dengan penerapannya dalam kehidupan seharihari.Dengan melibatkan siswa langsung dalam mengaitkan pengetahuannya, mengadakan perencanan penyelesaian bersama teman sekelompoknya, serta melakukan refleksi pada akhir kegiatan pembelajaran maka diharapkan kemampuan pemecahan masalah siswa turut meningkat.

Beberapa penelitian sebelumnya yaitu Suratno menyatakan bahwa model pmebelajaran kooperatif tipe Jigsaw lebih efektif ditinjau dari prestasi belajar matematika dan karakter siswa.selain itu, hasil penelitian Noviyani Florentina menyatakan bahwa kemampuan berfikir kreatif peserta didik yang diajarkan menggunakan model pmebelajaran kooperatif tipe Jigsaw lebih baik daripada model pembelajaran kooperatif tipe TPS. Sehingga berdasarkan uraian diatas peneliti tertarik melakukan penelitian dengan mengangkat judul :"Perbedaan Model Pembelajaran Kooperatif Tipe TPS (Think Pair Share) dan JigsawT erhadap Kemampuan Pemecahan Masalah Matematika Siswa Pada Pokok Bahasan Sistem Persamaan Linier Dua Variabel di Kelas VIII SMP Swasta MelatiKec. Hamparan Perak Kab.Deli Serdang Tahun Ajaran 2018/2019".

II. Metode Penelitian

Penelitian ini dilaksanakan di SMP Swasta Melati Kec.Hamparan Perak Kab.Deli Serdang.Penelitian ini dilakukan pada semester ganjil tahun ajaran 2018/2019 dengan Pokok Bahasan Sistem Persamaan Linier Dua Variabel di Kelas VIII SMP Swasta Melati

Populasi penelitian ini adalah seluruh siswa yang duduk dikelas VIII SMP Swasta Melati Kec.Hamparan Perak Kab.Deli Serdang Tahun Pelajaran 2018/2019 sebanyak 107 siswa yang terdiri dari empat kelas. Sampel dalam penelitian ini dipilih secara probability sampling dengan teknik cluster random sampling. Sugiyono menjelaskan cluster random sampling adalah teknik mengambil sampel bukan didasarkan individu, melaikan didasarkan kelompok atau subjek yang secara alami berkumpul bersama. Peneliti

mengambil kelas $\mathrm{VIII}_{2}$ dan $\mathrm{VIII}_{3}$ sebagai kelas eksperimen pertama dan kedua dengan diberikan perlakuan model pembelajaran TPS dan Jigsaw. Pertimbangan peneliti mengambil kelas tersebut karena peneliti telah melakukan studi pendahuluan pada kelas tersebut sehingga diharapkan hasilnya sesuai tujuan penelitian ini.

Variabel pertama di kelas eksperimen pertama adalah model pembelajaran Think Pair Share (TPS) dan variabel kedua adalah kemampuan pemecahan masalah matematika.Sedangkan dikelas eksperimen kedua variabel pertamanya adalah model pembelajaran kooperatif tipe Jigsaw dan variabel keduanya adalah kemampuan pemecahan masalah matematika.

Pola desain penelitian yang digunakan adalah non equivalent group pretest-posttes design. Desain ini tidak dipilih secara random. Desain ini digambarkan sebagai berikut :

\section{Tabel 1 Desain Penelitian}

\begin{tabular}{lccc}
\hline Kelompok & $\begin{array}{c}\text { Pengukuran I } \\
\text { (Pretest) }\end{array}$ & $\begin{array}{c}\text { Per- } \\
\text { lakuan }\end{array}$ & $\begin{array}{c}\text { Pengukur } \\
\text { an II } \\
\text { posttest) }\end{array}$ \\
\hline $\begin{array}{l}\text { Eksperimen } \\
E_{1}\end{array}$ & $\boldsymbol{a}_{1}$ & $\boldsymbol{P}_{1}$ & $\boldsymbol{b}_{1}$ \\
\hline $\begin{array}{l}\text { Eksperimen } \\
E_{2}\end{array}$ & $\boldsymbol{a}_{2}$ & $\boldsymbol{P}_{2}$ & $\boldsymbol{b}_{2}$ \\
\hline
\end{tabular}

Keterangan :

$E_{1} \quad$ : Kelas Eksperimen pertama

$E_{2} \quad$ : Kelas Eksperimen kedua

$P_{1}$ :Perlakuan terhadap kelompok ekperimen pertama dengan model pembelajaran Think Pair Share (TPS). 
$P_{2}$ : Perlakuan terhadap kelompok ekperimen kedua dengan model pembelajaranJigsaw.

$a_{1} \quad$ : Tes awal (Pre-Test) diberikan sebelum diberikan perlakuan pembelajaran pada kelas eksperimen pertama.

$b_{2} \quad$ : Tes akhir (Post-Test) diberikan setelah diberikan perlakuan pembelajaran pada kelas eksperimen pertama.

$a_{2}$ : Tes awal (Pre-Test) diberikan sebelum diberikan perlakuan pembelajaran pada kelas eksperimen kedua.

$b_{4}$ : Tes akhir (Post-Test) diberikan setelah diberikan perlakuan pembelajaran pada kelas eksperimen kedua.

Dalam penelitian ini ada dua variabel yang akan diteliti, yaitu :Variabel bebas:
1. $x_{1}$
Model
Pembelajaran

Kooperatif tipe Think Pair Share.
2. $x_{2}$ : Model Pembelajaran Kooperatif tipe Jigsaw.

Variabel terikat dalam penelitian ini adalah kemampuan pemecahan masalah matematika siswa pada pokok bahasan SPLDV.

Selain itu, peneliti juga melakukan uji coba tes tersebut untuk melihat validitas tes dan realibilitas tes, tingkat kesukaran soal, dan daya beda soal.

Tabel 2 Hasil Perhitungan Validitas Soal Pre-test dan Post-test

Kelas TPS

\begin{tabular}{ccccccc}
\hline \multirow{2}{*}{ No Soal } & \multicolumn{3}{c}{ Pre-test } & \multicolumn{3}{c}{ Post-test } \\
\cline { 2 - 7 } & $\boldsymbol{r}_{\text {hitung }}$ & $\boldsymbol{r}_{\text {tabel }}$ & Keterangan & $\boldsymbol{r}_{\boldsymbol{h i t u n g}}$ & $\boldsymbol{r}_{\boldsymbol{t a b e l}}$ & Keterangan \\
\hline $\mathbf{1}$ & 0,410 & 0,374 & Valid & 0,763 & 0,374 & Valid \\
\hline $\mathbf{2}$ & 0,668 & 0,374 & Valid & 0,812 & 0,374 & Valid \\
\hline $\mathbf{3}$ & 0,639 & 0,374 & Valid & 0,645 & 0,374 & Valid \\
\hline $\mathbf{4}$ & 0,653 & 0,374 & Valid & 0,747 & 0,374 & Valid \\
\hline $\mathbf{5}$ & 0,622 & 0,374 & Valid & 0,638 & 0,374 & Valid \\
\hline
\end{tabular}

Kelas Jigsaw

\begin{tabular}{ccccccc}
\hline No Soal & \multicolumn{3}{c}{ Pre-test } & \multicolumn{2}{c}{ Post-test } \\
\cline { 2 - 7 } & $\boldsymbol{r}_{\text {hitung }}$ & $\boldsymbol{r}_{\text {tabel }}$ & Keterangan & $\boldsymbol{r}_{\text {hitung }}$ & $\boldsymbol{r}_{\text {tabel }}$ & Keterangan \\
\hline $\mathbf{1}$ & 0,763 & 0,374 & Valid & 0,410 & 0,374 & Valid \\
\hline $\mathbf{2}$ & 0,812 & 0,374 & Valid & 0,668 & 0,374 & Valid \\
\hline $\mathbf{3}$ & 0,645 & 0,374 & Valid & 0,639 & 0,374 & Valid \\
\hline $\mathbf{4}$ & 0,747 & 0,374 & Valid & 0,653 & 0,374 & Valid \\
\hline $\mathbf{5}$ & 0,638 & 0,374 & Valid & 0,622 & 0,374 & Valid \\
\hline
\end{tabular}

Tabel 3 Hasil Perhitungan Reliabilitas Soal Pre-test dan Post-test

Kelas TPS

\begin{tabular}{cccc}
\hline Soal & $\boldsymbol{r}_{\text {hitung }}$ & $\boldsymbol{r}_{\text {tabel }}$ & Keterangan \\
\hline Pre-test & 0,563 & 0,374 & Reliabel \\
\hline Post-test & 0,771 & 0,374 & Reliabel \\
\hline
\end{tabular}

Kelas Jigsaw

$\begin{array}{llll}\text { Soal } & r_{\text {hitung }} & r_{\text {tabel }} & \text { Keterangan }\end{array}$




\begin{tabular}{cccc}
\hline Pre-test & 0,771 & 0,374 & Reliabel \\
\hline Post-test & 0,563 & 0,374 & Reliabel \\
\hline
\end{tabular}

Tabel 4 Hasil Perhitungan Indeks Kesukaran Soal Pre-test dan Post-test

Kelas TPS

\begin{tabular}{|c|c|c|c|c|c|c|c|c|}
\hline \multirow[t]{2}{*}{ No. } & \multicolumn{4}{|c|}{ Pre - test } & \multicolumn{4}{|c|}{ Post - test } \\
\hline & B & JS & $\mathbf{P}$ & Kategori & B & JS & $\mathbf{P}$ & Kategori \\
\hline 1 & 150 & 280 & 0,54 & Sedang & 159 & 280 & 0,57 & Sedang \\
\hline 2 & 110 & 280 & 0,39 & Sedang & 151 & 280 & 0,54 & Sedang \\
\hline 3 & 143 & 280 & 0,51 & Sedang & 157 & 280 & 0,56 & Sedang \\
\hline 4 & 133 & 280 & 0,48 & Sedang & 132 & 280 & 0,47 & Sedang \\
\hline 5 & 99 & 280 & 0,35 & Sedang & 124 & 280 & 0,44 & Sedang \\
\hline \multicolumn{9}{|c|}{ Kelas Jigsaw } \\
\hline \multirow{2}{*}{ No. } & \multicolumn{4}{|c|}{ Pre - test } & \multicolumn{4}{|c|}{ Post - test } \\
\hline & B & JS & $\mathbf{P}$ & Kategori & B & JS & $\mathbf{P}$ & Kategori \\
\hline 1 & 159 & 280 & 0,57 & Sedang & 150 & 280 & 0,54 & Sedang \\
\hline 2 & 151 & 280 & 0,54 & Sedang & 110 & 280 & 0,39 & Sedang \\
\hline 3 & 157 & 280 & 0,56 & Sedang & 143 & 280 & 0,51 & Sedang \\
\hline 4 & 132 & 280 & 0,47 & Sedang & 133 & 280 & 0,48 & Sedang \\
\hline 5 & 124 & 280 & 0,44 & Sedang & 99 & 280 & 0,35 & Sedang \\
\hline
\end{tabular}

Tabel 5 Hasil Perhitungan Daya Beda Soal Pre-test dan Post-test

Kelas TPS

\begin{tabular}{ccccc}
\hline No & \multicolumn{2}{c}{ Pre-test } & \multicolumn{2}{c}{ Post-test } \\
\cline { 2 - 5 } & Daya Beda Soal & Kategori & Daya Beda Soal & Kategori \\
\hline $\mathbf{1}$ & 0,086 & Buruk & 0,179 & Buruk \\
\hline $\mathbf{2}$ & 0,229 & Cukup & 0,250 & Cukup \\
\hline $\mathbf{3}$ & 0,221 & Cukup & 0,221 & Cukup \\
\hline $\mathbf{4}$ & 0,250 & Cukup & 0,229 & Cukup \\
\hline $\mathbf{5}$ & 0,321 & Cukup & 0,229 & Cukup \\
\hline
\end{tabular}

\section{Kelas Jigsaw}

\begin{tabular}{ccccc}
\hline \multirow{2}{*}{ No } & \multicolumn{2}{c}{ Pre-test } & \multicolumn{2}{c}{ Post-test } \\
\cline { 2 - 5 } & Daya Beda Soal & Kategori & Daya Beda Soal & Kategori \\
\hline $\mathbf{1}$ & 0,179 & Buruk & 0,086 & Buruk \\
\hline $\mathbf{2}$ & 0,250 & Cukup & 0,229 & Cukup \\
\hline $\mathbf{3}$ & 0,221 & Cukup & 0,221 & Cukup \\
\hline $\mathbf{4}$ & 0,229 & Cukup & 0,250 & Cukup \\
\hline $\mathbf{5}$ & 0,229 & Cukup & 0,321 & Cukup \\
\hline
\end{tabular}

\section{Pembahasan} uji statistic yang digunakan, terlebih

Peneliti juga melakukan Analisis data dilakukan untuk menguji hipotesis yang telah dirumuskan. Untuk menentukan 
uji normalitas data dan homogenitas

Berikut hasil dari analisis data : variansi.

Tabel 6 Ringkasan Rata-rata Nilai Pretes dan Postes (TPS)

\begin{tabular}{ccc}
\hline Keterangan & \multicolumn{2}{c}{ Kelas Eksperimen } \\
\cline { 2 - 3 } & Pretes & Postes \\
\hline Jumlah nilai & 805 & 1940 \\
\hline Rata-rata & 28,75 & 69,28 \\
\hline
\end{tabular}

Ringkasan Rata-rata Nilai Pretes dan Postes (Jigsaw)

\begin{tabular}{ccc}
\hline Keterangan & \multicolumn{2}{c}{ Kelas Eksperimen } \\
\cline { 2 - 3 } & Pretes & Postes \\
\hline Jumlah nilai & 1940 & 805 \\
\hline Rata-rata & 69,28 & 28,75 \\
\hline
\end{tabular}

Pengujian

normalitas

data dilakukan dengan uji lilliefors dengan ketentuan jika $L_{o}<L_{\text {tabel }}$ maka disimpulkan bahwa sebaran data berdistribusi normal dan demikian sebaliknya. Uji normalitas data pretes kelas eksperimen (TPS) diperoleh $L_{o}(0,1189)<L_{\text {tabel }}(0,166)$. Data postes kelas eksperimen diperoleh $L_{o}(0,1509)<$ $L_{\text {tabel }}(0,166)$. Sedangkan data pretest kelas eksperimen (Jigsaw) $L_{o}(0,1509)<L_{\text {tabel }}($ $0,166)$ sedangkan data postes kelas eksperimen $\quad L_{o}(0,1189)<$ $L_{\text {tabel }}(0,166)$.

Tabel 7 Ringkasan Hasil Uji Normalitas Data dengan Liliefors (TPS)

\begin{tabular}{|c|c|c|c|}
\hline \multirow[t]{2}{*}{ Data } & \multicolumn{3}{|c|}{ Kelas Eksperimen } \\
\hline & $L_{\text {hitung }}$ & $L_{\text {tabel }}$ & Keterangan \\
\hline Pre tes & 0,1189 & 0,166 & Normal \\
\hline Post test & 0,1509 & 0,166 & Normal \\
\hline \multicolumn{4}{|c|}{ Ringkasan Hasil Uji Normalitas Data dengan Liliefors } \\
\hline \multirow[t]{2}{*}{ Data } & \multicolumn{3}{|c|}{ Kelas Eksperimen } \\
\hline & $L_{\text {hitung }}$ & $L_{\text {tabel }}$ & Keterangan \\
\hline Pre tes & 0,1509 & 0,166 & Normal \\
\hline Post test & 0,1189 & 0,166 & Normal \\
\hline
\end{tabular}

Untuk menguji homogenitas dari data yang diperoleh selama penelitian, digunakan uji statistic-F.untuk kriteria pengujian data sampel adalah homogeny jika $F_{\text {hitung }}<$ $F_{\text {tabel }}$ pada taraf nyata $\alpha=0,05 . \quad \mathrm{Uji}$ homogenitas pretes pada kemampuan 
pemecahan masalah kelas eksperimen (TPS) dan (Jigsaw) diperoleh $F_{\text {hitung }}(1,345)<$ $F_{\text {tabel }}(1,88)$ dan data postes kemampuan pemecahan masalah kelas eksperimen diperoleh $\quad F_{\text {hitung }}(1,345)<F_{\text {tabel }}(1,88)$.

Tabel 8 Data Hasil Uji Homogenitas (TPS dan Jigsaw)

\begin{tabular}{cccc}
\hline Data & $\boldsymbol{F}_{\text {hitung }}$ & $\boldsymbol{F}_{\text {tabel }}$ & Keterangan \\
\hline Pretes & 1,345 & 1,88 & Homogen \\
\hline Postes & 1,345 & 1,88 & Homogen \\
\hline
\end{tabular}

Setelah diketahui bahwa untuk data kemampuan pemecahan masalah matematis berdistribusi normal dan homogeny, selanjutnya dilakukan pengujian hipotesis. Pengujian hipotesis ini diujikan dengan menggunakan Uji-t dengan kriteria jika $t_{\text {hitung }}>t_{\text {tabel }}$ berarti $H_{0}$ ditolak dan $H_{a}$ diterima. Hasil perhitungan uji hipotesis penelitian ditunjukan pada tabel 9 berikut ini.sedangkan hasil selengkapnya dapat ditunjukan di lampiran .

Tabel 9 Ringkasan Hasil Perhitungan Nilai Uji-t

\begin{tabular}{ccccc}
\hline Variabel & Dk & $\boldsymbol{t}_{\text {hitung }}$ & $\boldsymbol{t}_{\text {tabel }}$ & Kesimpulan \\
\hline (Pretest) & 27 & 2,292 & 1,70 & Ada Pengaruh \\
\hline (Posttest) & 27 & 19,21 & 1,70 & Ada Pengaruh
\end{tabular}

Berdasarkan kriteria Uji-t, jika $t_{\text {hitung }}>t_{\text {tabel }}$ maka $H_{a}$ diterima. Dari hasil analisis diatas maka $H_{a}$ diterima yang menyatakan bahwa "Terdapat perbedaan model pembelajaran kooperatif tipe think pair

\section{Kesimpulan dan Saran}

Berdasarkan hasil penelitian yang diperoleh dari analisis data diperoleh kesimpulan yaitu terdapat perbedaan signifikan Model Pembelajaran Kooperatif Tipe Think Pair Share (TPS) Dan Jigsaw Terhadap Kemampuan Pemecahan Masalah Matematika Siswa Di Kelas VIII SMP Swasta Melati Kec. Hamparan Perak Kab.Deli Serdang Tahun Ajaran 2018/2019.

\section{B. Saran}

Berdasarkan hasil penelitian ini maka saran yang didapat peneliti berikan adalah:

1. Bagi siswa agar terlihat lebih aktif dalam pembelajaran seperti share (TPS) dan jigsaw terhadap kemampuan pemecahan masalah matematika siswa di kelas VIII SMP Swasta Melati Kec. Hamparan Perak Kab.Deli Serdang tahun ajaran 2018/2019”.

\section{A. Kesimpulan}

mengeluarkan pendapat dan ide-ide pengetahuan baru. Sehingga pengetahuan yang didapatkan adalah pengetahuan bermakna yang bukan sekedar hafalam yang selanjutnya dapat diaplikasikan untuk menyelesaikan soal-soal.

2. Kepada guru matematika dapat menerapkan model pembelajaran kooperatif tipe Think Pair Share (TPS) sebagai model pembelajaran yang diharapkan dapat membuat siswa menjadi lebih aktif dalam mengikuti pelajaran. 
3. Kepada guru matematika yang ingin menerapkan model pembelajaran kooperatif tipe Think Pair Share (TPS) sebaiknya dapat memanfaatkan waktu dengan sebaik-baiknya agar proses pembelajaran dapat berjalan dengan baik.

Kepada calon peneliti berikutnya agar mengadakan penelitian yang sama dengan materi atau kelas yang berbeda sehingga hasil penelitian dapat berguna bagi kemajuan pendidikan khususnya pendidikan matematika.

\section{DAFTAR PUSTAKA}

Ali Hamzah,dkk, Perencanaan dan Strategi Pembelajaran Matematika (Jakarta: Raja Grafindo Persada,2014).

Bintang Wicaksono, dkk, Model pembelajaran group Invetigation (GI) dan Think Pair Share (TPS) Terhadap Kemampuan berfikir ktitis. Vol 8 No. 2 November 2017.

Effendi Zakaria,dkk Trend Pengajaran Dan Pembelajaran Matematik, (Kuala Lumpur : PRIN-AD,SDN,BHD,2007) .

Ichwanu, Pengembangan Perangkat Pembelajaran Matematika Menggunakan Lembar Kerja Sosial Alternatif Untuk Siswa SMP Kelas VII Dalam Pemecahan Masalah Tentang Segiempat dan Segitiga Jurnal Pendidikan Matematika Volume 3 No 3 Tahun 2014.

Ike Nataliasari,Penggunaan Model Pembelajaran Kooperatif Tipe Think Pair Share (TPS) Untuk Meningkatkan Kemampuan Penlaran dan Pemecahan Masalah Matematis Siswa. Vol. 1 No.1, 2014, artikel 3.

Istarani, 58 Model Pembelajaran Inovatif,(Medan:MediaPersada,2015).
Jakni, Metodologi Penelitian Eksperimen Bidang Pendidikan, (Bandung : Alfabeta ,2016). 